\title{
Valproic Acid Alters Angiogenic and Trophic Gene Expression in Human Prostate Cancer Models
}

\author{
RAJU CHELLURI $^{1}$, TIFFANY CAZA ${ }^{2}$, MARK R. WOODFORD ${ }^{1}$, JAY E. REEDER ${ }^{3}$, \\ GENNADY BRATSLAVSKY ${ }^{1}$ and TIMOTHY BYLER ${ }^{1}$ \\ Departments of ${ }^{1}$ Urology and ${ }^{2}$ Pathology, State University of New York, \\ Upstate Medical University, Syracuse, NY, U.S.A.; \\ ${ }^{3}$ Department of Obstetrics and Gynecology, University of Rochester Medical Center, Rochester, NY, U.S.A.
}

\begin{abstract}
Background/Aim: Only a minority of men succumb to prostate cancer $(\mathrm{PC}$ ) $)$. Therapy to prevent progression would change treatment paradigms. We investigated the effect of valproic acid (VPA) on PCa cell proliferation and the effects on both angiogenesis and PCa-specific signaling. Materials and Methods: LNCaP cells were treated with VPA for $72 h$ and proliferation was measured. Cellular RNA extracts were used to measure gene expression with RTprofiler $^{2}$ arrays. Genes with alterations were validated using real-time polymerase chain reaction and western blot. Results: VPA led to a dose-dependent decrease in proliferation. Expression array data revealed an impact on modulators of angiogenesis. Additionally, several cell-cycle control transcripts were affected. There was a strong correlation between gene and protein expression levels for validated targets. Conclusion: VPA decreases cellular proliferation of $P C$ a cells in vitro and also affects gene expression suggestive of anti-angiogenic effect with a concomitant decrease in proliferation-related genes.
\end{abstract}

In 2015, there were an estimated 220,800 incident cases of prostate cancer ( $\mathrm{PCa}$ ) with 27,540 patient deaths (1). Despite these sobering statistics, a majority of disease continues to be low-grade in nature with an excellent prognosis. Often, the complications of therapy can outweigh the risk of lowgrade cancers that have reduced oncologic potential. There remains a need for therapy in these low-risk cancers that can

This article is freely accessible online.

Correspondence to: Dr. Timothy Byler, MD, SUNY Upstate Medical University, Department of Urology, 750 East Adams Street, Syracuse, NY 13210, U.S.A. Tel: +1 3154644473, Fax: +1 3154646117, e-mail: bylert@upstate.edu

Key Words: Prostatic neoplasms, histone deacetylase inhibitors, neovascularization, pathologic, valproic acid, thrombospondin 1 . halt progression to higher-risk disease while minimizing the morbidity of treatment.

Chemoprevention via anti-angiogenic therapy (AAT) is a targeted strategy that could limit further tumor growth. As a tumor continues to grow, there is development of an impaired blood supply and a resultant hypoxic tumor microenvironment. It is hypothesized that this stress may allow cancerous lesions to evade immune surveillance and, ultimately, may apply selective pressure favoring cells that possess invasive and metastatic capability (2). With this in mind, AAT early in $\mathrm{PCa}$ development could restore a normal tumor microenvironment by alleviating hypoxia and, thus, halting progression. These effects stem from the "normalizing" effects on the vasculature by prudent AAT use. Consistent with this, in vitro and murine models have demonstrated that AAT is more effective when the PCa burden is minimal (3).

While some AAT directly target vascular endothelial growth factor (VEGF) or its effectors, one mechanism that has received less investigation is epigenetic modification, in particular the acetylation of histones. Cancerous cells are able to alter their histone acetylation status and, thus, gene expression (4). Therapies that act as histone deacetylase inhibitors (HDACi) can modulate this phenomenon (5). HDACi have been tested in multiple in vitro and in vivo cancer models (6), as well as progressing to clinical trials (7).

One of the well-known and commonly used HDAC inhibitors is valproic acid (VPA) (8), which has been safely used for over 50 years as an anti-seizure medication. We have previously shown that VPA decreases urothelial cancer cell proliferation and induces the expression of thrombospondin-1 (TSP1), an extracellular matrix protein that functions as a potent inhibitor of angiogenesis (9). We sought to investigate the intracellular signaling alterations caused by VPA administration to PCa cells. Our hypothesis was that VPA would inhibit PCa growth through modifications in both angiogenic signaling and pathways known to be associated with $\mathrm{PCa}$ growth and progression. Furthermore, we postulated that TSP1 would be a central regulator in these signaling cascades. 


\section{Materials and Methods}

Cell culture. The androgen-sensitive LNCaP clone FGC (CRL$1740^{\mathrm{TM}}$ ) PCa cell line was purchased from the American Type Culture Collection (ATCC, Manassas, VA, USA). These cells were cultured in RPMI 1640 (Corning, Tewksbury, MA, USA) media with $10 \%$ fetal bovine serum and $5 \%$ penicillin/streptomycin. Cells were incubated at $37^{\circ} \mathrm{C}$ in atmosphere containing $5 \% \mathrm{CO}_{2}$.

Treatments. Sodium valproate was purchased from Westward pharmaceuticals (Eatontown, NJ, USA) as a stock $100 \mathrm{mg} / \mathrm{ml}$ solution and stored at room temperature as previously described (9).

Proliferation assay. LNCaP were plated in quadruplicate at $30 \%$ confluency in a 24-well plate and incubated overnight. Media was replaced the following day with media containing VPA and incubated for $72 \mathrm{~h}$. Media was aspirated and replaced with $300 \mu \mathrm{l}$ media containing $10 \%$ alamar blue. Absorbance measurements at 570 and $600 \mathrm{~nm}$ were taken hourly for four hours. The ratio of absorbance at 570 to $600 \mathrm{~nm}$ was scaled from zero for the unseeded wells to $100 \%$ for the untreated wells.

RNA harvest and cDNA synthesis. LNCaP cells were grown in $75 \mathrm{~cm}^{2}$ flasks (Corning) until 50\% confluency and treated once with $1 \mathrm{mM}$ VPA. After $72 \mathrm{~h}$, cells were scraped into a PBS solution and RNA was harvested using RNAeasy (Qiagen, Valencia, CA, USA) kit as per manufacturer's instructions. RNA was quantified using NanoDrop spectrophotometer (Wilmington, Delaware, USA) at $260 \mathrm{~nm}$. Reverse transcription was performed using Bio-Rad iScript cDNA synthesis kit (Hercules, CA, USA) as per manufacturer's instructions to yield 1,000 ng of cDNA.

Expression arrays. Human Angiogenesis $\mathrm{RT}^{2}$ Profiler $^{\mathrm{TM}}$ and Human Prostate Cancer RT ${ }^{2}$ Profiler RNA RT-PCR Arrays were purchased from SABiosciences (Qiagen, Valencia, CA, USA). Both Human Angiogenesis and Human Prostate Cancer templates were used to screen gene expression alterations caused by VPA in LNCaP cells. Arrays were run as per manufacturer's instructions with 1,000 ng of RNA from untreated and $1 \mathrm{mM}$ VPA-treated LNCaP cells using Biorad iTaq Universal SYBR Green Master mix as described below.

Real-time polymerase chain reaction (RT-PCR). Bio-rad iTaq Universal SYBR Green Master mix was used for RT-PCR reactions as per manufacturer's instructions. PCR primers spanned two exons. Each reaction was run in triplicate on a Bio-Rad CFX Connect light cycler.

RNA expression data analysis. The reference genes selected were RPL13A, HPRT-1 and RPLO $(10,11)$. RT profiler data were analyzed using SABiosciences data analysis software (http:// pcrdataanalysis. sabiosciences.com/pcr/arrayanalysis.php). In validation studies the $\Delta \Delta \mathrm{CT}$ method was used to calculate relative fold change as done previously (9).

Protein extraction and western blotting. All protein-based experiments were conducted as described previously (12). Primary antibodies for Akt1 (\#9272), Cyclin D1, (\#2922) and Cyclin D2 (\#3741) were obtained from Cell Signaling (Danvers, MA, USA). TSP1 (sc-59887) was obtained from Santa Cruz Biotechnology (Dallas, TX, USA) and $\beta$-actin (ab8227) was purchased from Abcam (Cambridge, MA, USA).

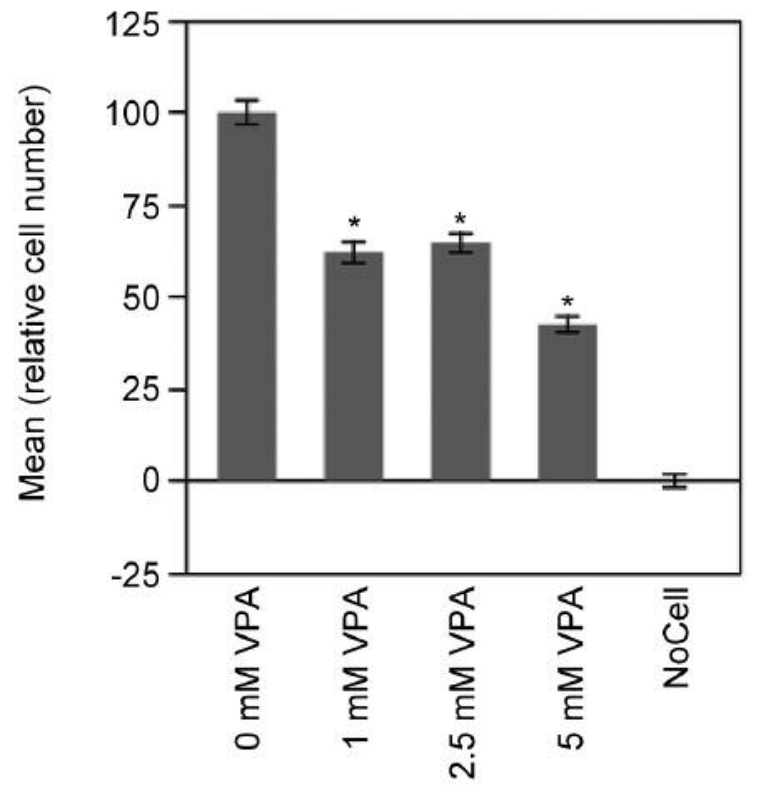

Figure 1. Proliferation inhibition of LNCaP cells in response to a doseescalation of VPA. Statistically significant differences from control are annotated with an asterisk ( $t$-test, $p<0.05$ ). All doses of VPA show a statistically significant reduction compared to no treatment.

Statistical analysis. T-tests were used to analyze proliferation data (JMP statistical software, Cary, NC, USA). Validation of gene expression was tested for statistical significance using one-way ANOVA (graph-pad prism 6.0 for Macintosh, La Jolla, CA, USA).

\section{Results}

Anti-proliferative effects of VPA. LNCaP cells were treated with 1, 2.5 and $5 \mathrm{mM}$ VPA as shown in Figure 1. Each dose demonstrated a significant reduction of proliferation compared to the untreated control. Additionally, proliferation further decreased as VPA increased to $5 \mathrm{mM}$.

Expression array analysis. Waterfall plots illustrating gene expression changes induced by $1 \mathrm{mM}$ VPA for the Angiogenesis and Prostate Cancer $\mathrm{RT}^{2}$ Profiler $^{\mathrm{TM}}$ Gene Expression Arrays are shown in Figure 2A and B, respectively. As can be seen from the graph, the expression of anti-angiogenic secreted extracellular matrix proteins, such as TSP1 (named THBS1 on waterfall graph) and tissue inhibitor of matrix metalloproteinases (TIMP) 1,2 and 3 was increased. The brain-specific angiogenesis inhibitor 1 (BAII) was increased in expression in concert with increased levels of angiogenic stimulators nitric oxide (NO) synthetase 3 (NOS3) and $V E G F-B$ isoform. $V E G F-A$ expression was decreased. Transforming growth factor beta (TGF $\beta$ ) expression was increased, while its receptor was decreased. 


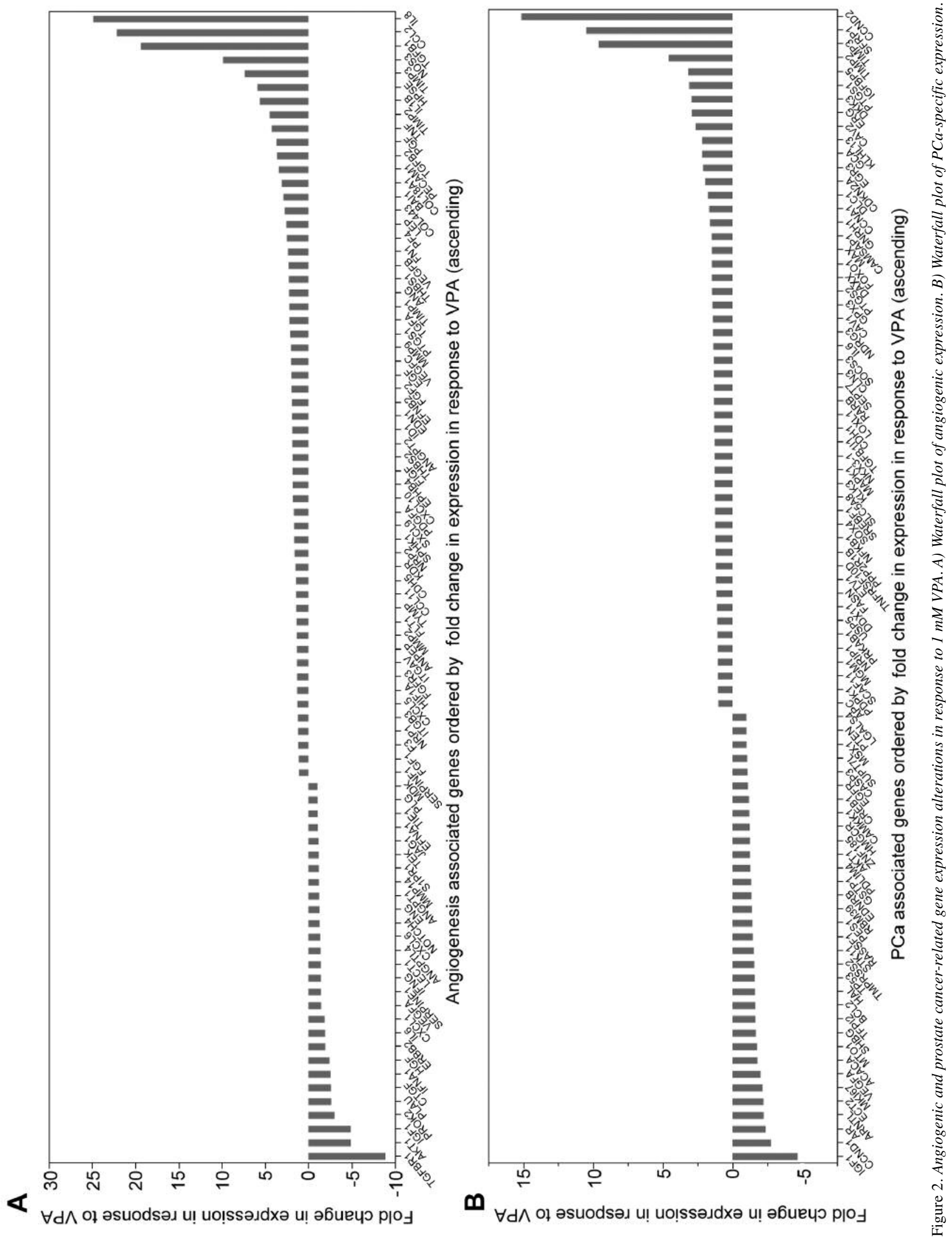



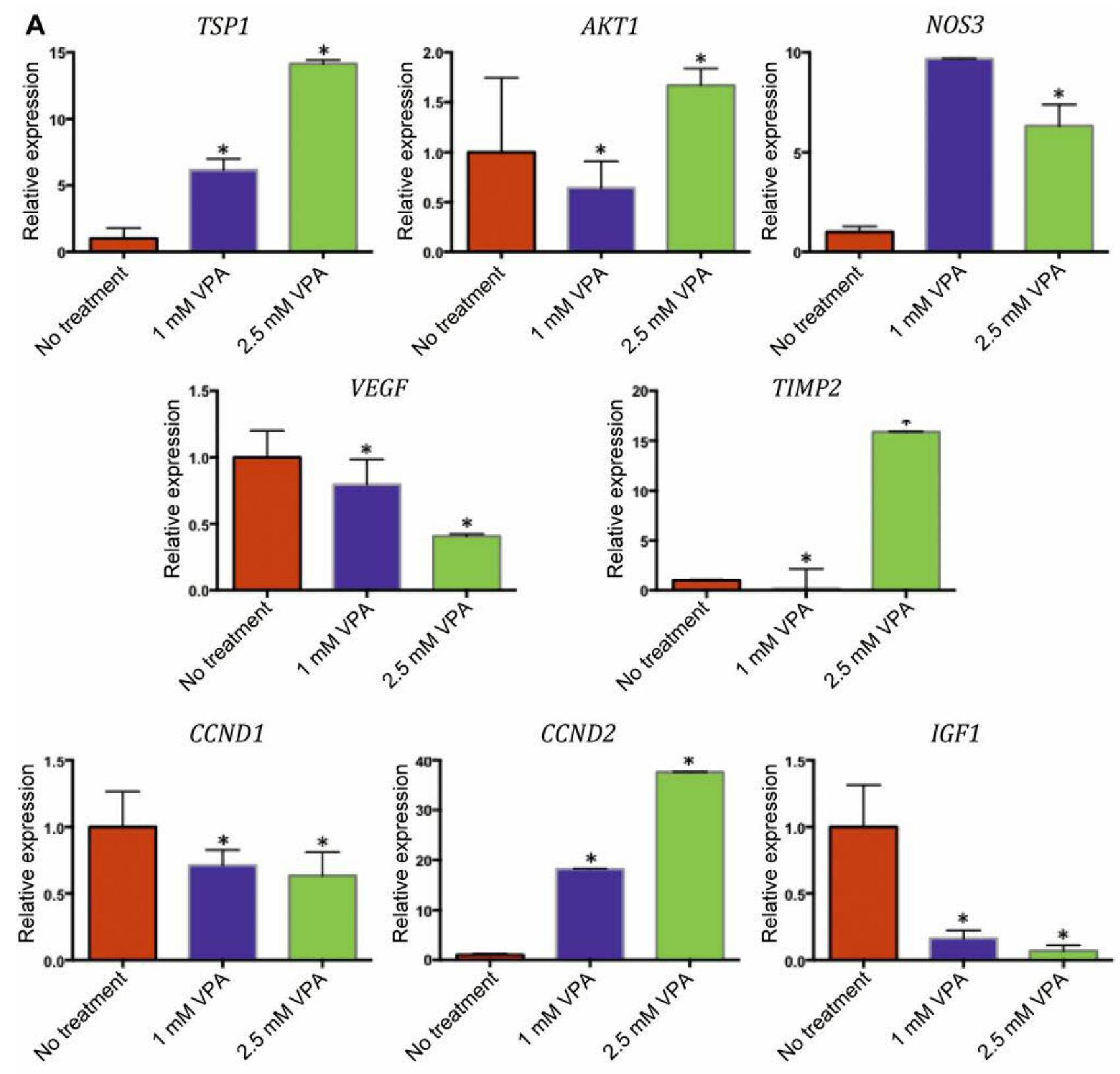

CCND2

IGF1
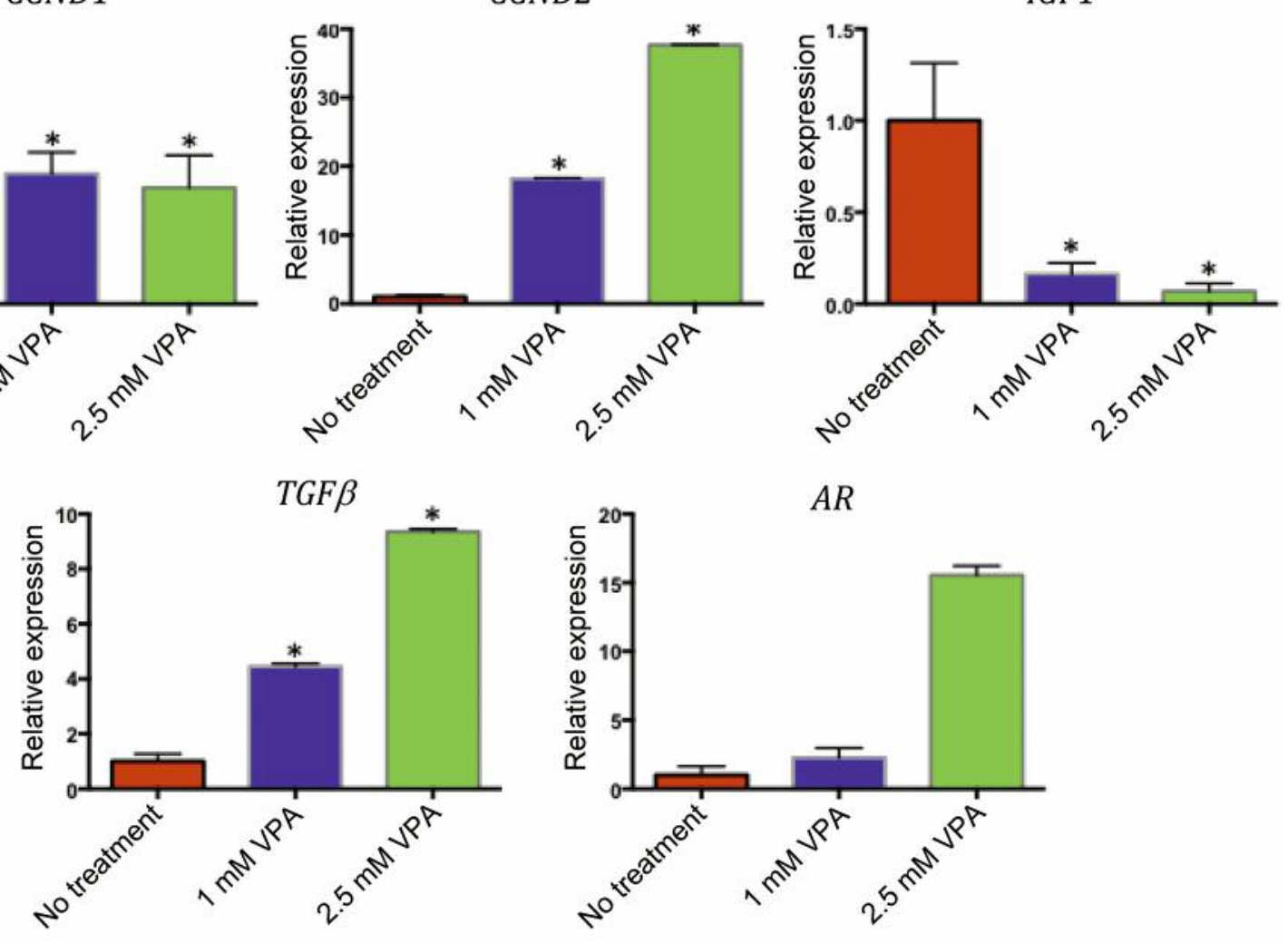

Figure 3. Continued 


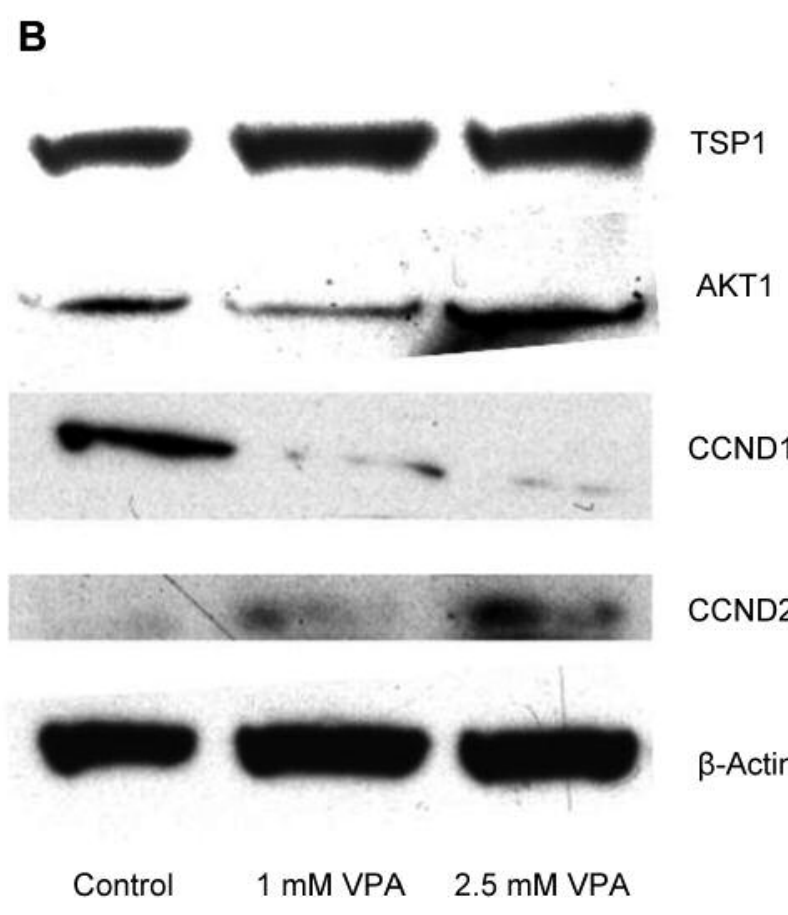

Figure 3. Validation of selected genes from expression arrays. Five genes from each array were selected for validation at the RNA level. Two of these five were further confirmed at the protein level. A: Relative gene expression changes are illustrated, grouped by array (ANOVA, $p<0.05)$. B: Two targets from each group were further validated at the protein level

In terms of PCa-specific signaling, the expression of trophic molecules, such as insulin-like growth factor 1 (IGF1) and the androgen receptor $(A R)$ were reduced. Interestingly, a carrier protein for IGF, insulin-like growth factor binding protein 5 (IGFBP5) showed increased expression. Several cell-cycle transcripts were impacted, including down-regulation of protein kinase $\mathrm{B}(A K T 1)$ and cyclin $\mathrm{D} 1$ (CCND1), while cyclin D2 (CCND2) was increased.

\section{Targeted gene and protein expression validation}

Angiogenesis. Genes with major alterations in expression from the array analysis were selected for validation. RNA and protein expression was measured in cells dosed with VPA $(0,1,2.5 \mathrm{mM})$ for $72 \mathrm{~h}$. These genes were grouped by the array from whence they came. For angiogenic gene expression (Figure 3A), TSP1 showed a dose dependent increase in expression. AKT1 decreased at $1 \mathrm{mM}$ as expected, yet increased in expression above baseline at 2.5 $\mathrm{mM}$. NOS3 increased expression at $1 \mathrm{mM}$ VPA, as it did on the array, yet this was attenuated as the VPA dose was raised to $2.5 \mathrm{mM}$. TIMP2 decreased in expression at $1 \mathrm{mM}$, as on the array, but sharply increased at $2.5 \mathrm{mM}$. VEGF-A, which did not significantly decrease in expression on the angiogenesis array, followed this decreasing pattern on validation analysis, and continued to significantly decrease at the highest VPA dose. At the protein level, TSP1 and Akt1 expression matched with the gene expression array data (Figure 3B).

Prostate cancer-specific signaling. The PCa specific genes $C C N D 1, C C N D 2, T G F \beta$ and $I G F 1$ followed the expression pattern seen on the arrays (Figure 3A). The AR, however, while increasing slightly in expression at $1 \mathrm{mM}$ (as opposed to the $\sim 2.5$-fold decrease seen on the array), increased to a much higher expression level at $2.5 \mathrm{mM}$ VPA, though this increase was not statistically significant. CCND1 and CCND2 protein levels changed similarly to the RNA expression alterations observed (Figure 3B).

\section{Discussion}

In the present study we examined the effects of VPA administration on LNCaP cells to understand the effects that VPA has on angiogenic and trophic gene expression. Consistent with previous studies, we demonstrated VPA decreases LNCaP proliferation, with a trend towards dosedependency (13). Next, we illustrated the broad effects of VPA on both angiogenic and PCa-related gene expression. Finally, we validated expression from our array analysis at the RNA and protein level in response to a dose escalation of VPA. These data demonstrate that VPA may induce a shift of the intracellular signaling environment away from lesion growth and towards decreasing angiogenic expression.

Our expression array and subsequent validation data reveal a marked impact by VPA on secreted and extracellular matrix proteins, including up-regulation of $T S P 1$, multiple TIMP isoforms and TGF $\beta$, while expression of IGFI and $V E G F$ were reduced. This supports VPA as a potential modulator of angiogenesis, migration and invasion of $\mathrm{PCa}$. We focused on TSP1 as this protein has been shown to inhibit endothelial cell proliferation, migration and neovascularization (14). Indeed, TSP1 is a critical regulator on the initiation of angiogenesis through suppression of VEGF and NO signaling (15). Clinically, it has been demonstrated that, as $\mathrm{PCa}$ progresses from prostatic intraepithelial neoplasia to invasive adenocarcinoma, TSP1 expression is lost (16). Other modulators of angiogenesis were affected concurrently with TSP1. Akt1 is known to stimulate cell survival, cell-cycle progression, metabolism and vascular tube formation (17). The TIMP family, and specifically TIMP2, inhibits angiogenesis and invasion (18). TIMP2 has been shown to be down-regulated or silenced in a variety of cancers via epigenetic inactivation (18). Our work confirms the effects of VPA on these pathways, thus highlighting a potential anti-angiogenic mechanism. 


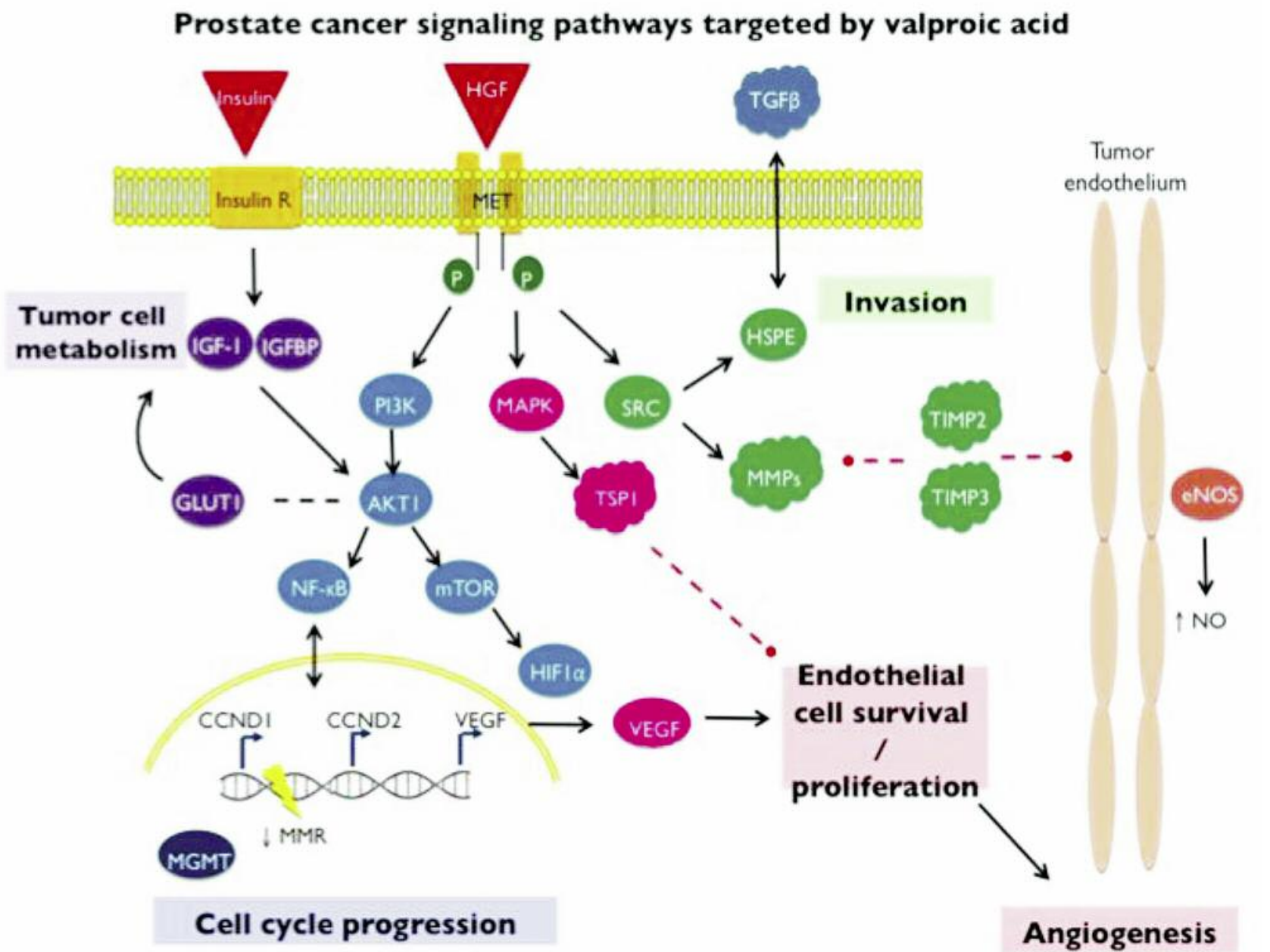

Figure 4. Valproic acid (VPA) mitigates trophic and angiogenic signaling within human prostate cancer cells. VPA inhibits angiogenesis through increasing TSP1 expression, which opposes angiogenesis through antagonizing VEGF. TSP1 also suppresses NO production and promotes apoptosis. This results in reduced endothelial cell survival and proliferation. TSP1 is repressed by CCND1 (which promotes cell cycle progression), which is also reduced by VPA. CCND2 is increased by VPA, which opposes CCND1 and has anti-proliferative effects. In addition to TSP1 and CCDN2 expression, an increase in expression of the tissue inhibitors of matrix metalloproteinases (TIMPs) further inhibits angiogenesis. TIMP expression also reduces tumor cell invasion through inhibiting matrix metalloproteinases. Therefore, VPA reduces prostate cancer cell survival in a multifaceted manner through inhibiting angiogenesis, reducing tumor cell invasion, supporting endothelial cell survival and promoting cell cycle progression.

While TSP1 is not necessarily known to be directly related to other, more broadly known trophic PCa regulators, we nonetheless demonstrated the effects of VPA in these cascades. For example, IGF1 is important for initiation PCa (19). Clinical data also support the role of IGF1 in increasing risk for PCa (20). TGF $\beta$ has been shown to have differential effects as $\mathrm{PCa}$ progresses, having inhibitory effects on growth in less mature lesions (21). The effect of the cyclins on PCa growth is less clear. CCND1 is a potent mitogen and has specific inhibitory effects on TSP1 through repressing its promoter (22). In contradistinction, CCND2 expression reduces proliferation by functioning as a tumor suppressor and this was validated in a report of VPA-mediated inhibition of PCa proliferation through re-expression of CCND2 (23). Our data appear to confirm this finding. The interplay of these various signals is illustrated graphically in Figure 4.

VPA has been studied in vitro and shown to be antiproliferative through many mechanisms, including the induction of cell cycle arrest and apoptosis (24). VPA administration also decreases PCa xenograft growth (25) without inducing neuroendocrine differentiation (26), limits microvessel density and can function as AAT through a decrease in eNOS expression in endothelial cells (27). Yet the clinical data of VPA is mixed, as a retrospective study 
showed a decreased risk of PCa (28), while another showed no effect (29). While a phase II study of VPA in castrateresistant $\mathrm{PCa}$ was ineffective (30), there are ongoing phase II studies of VPA in lower grade PCa (https:// clinicaltrials.gov/ct2/show/NCT00670046). This study may shed light on potential new PCa populations in which VPA could have utility.

Our study has a number of limitations. We did not validate all significantly altered genes on the arrays and we also performed western blots on selected, but not all genes validated by RT-PCR. Additionally, our study was performed in a single cell line that is androgen-sensitive and, therefore, we do not know if the same findings would be observed if multiple hormone-sensitive lines were used or our experiments were performed in a castrate-resistant environment Furthermore, we lack animal data. Despite these limitations, our data provide comprehensive assessment of angiogenesis and prostate cancer-specific signaling expression in the HDAC-treated prostate cancer cell line and may potentially be useful for future studies and assessment of therapeutic potential in prostate cancer patients.

\section{Conclusion}

The Authors have shown that VPA administration induces changes in proliferation and gene expression in a PCa model. They have also observed up-regulation of anti-angiogenic proteins, a promising mechanism for this potentially novel treatment for $\mathrm{PCa}$. This mechanism can be exploited in future PCa clinical trials.

\section{Ethical Standards}

This article does not contain any studies with human participants or animals performed by any of the Authors.

\section{Conflicts of Interest}

The Authors declare that they have no conflict of interest.

\section{References}

1 Siegel RL, Miller KD and Jemal A: Cancer statistics, 2015. CA Cancer J Clin 65: 5-29, 2015.

2 Jain RK: Antiangiogenesis strategies revisited: from starving tumors to alleviating hypoxia. Cancer Cell 26: 605-22, 2014.

3 Isayeva T, Chandra D, Kallman L, Eltoum IE and Ponnazhagan S: Effects of sustained antiangiogenic therapy in multistage prostate cancer in TRAMP model. Cancer Res 67: 5789-97, 2007.

4 Marks P, Rifkind RA, Richon VM, Breslow R, Miller T and Kelly WK: Histone deacetylases and cancer: causes and therapies. Nat Rev Cancer 1: 194-202, 2001.

5 Ellis L, Hammers H and Pili R: Targeting tumor angiogenesis with histone deacetylase inhibitors. Cancer Lett 280: 145-53, 2009 .
6 Yin D, Ong JM, Hu J, Desmond JC, Kawamata N, Konda BM, Black KL and Koeffler HP: Suberoylanilide hydroxamic acid, a histone deacetylase inhibitor: effects on gene expression and growth of glioma cells in vitro and in vivo. Clin Cancer Res 13: 1045-1052, 2007.

7 Soriano AO, Yang H, Faderl S, Estrov Z, Giles F, Ravandi F, Cortes J, Wierda WG, Ouzounian S, Quezada A, Pierce S, Estey EH, Issa JP, Kantarjian HM and Garcia-Manero G: Safety and clinical activity of the combination of 5-azacytidine, valproic acid, and all-trans retinoic acid in acute myeloid leukemia and myelodysplastic syndrome. Blood 110: 23022308, 2007.

8 Göttlicher M, Minucci S, Zhu P, Krämer $\mathrm{OH}$, Schimpf A, Giavara S, Sleeman JP, Lo Coco F, Nervi C, Pelicci PG and Heinzel T: Valproic acid defines a novel class of HDAC inhibitors inducing differentiation of transformed cells. EMBO J 20: 6969-6978, 2001.

9 Byler TK, Leocardio D, Shapiro O, Bratslavsky G, Stodgell CJ, Wood RW, Messing EM and Reeder JE: Valproic acid decreases urothelial cancer cell proliferation and induces thrombospondin1 expression. BMC Urol 12: 1186/1471-12-21, 2012.

10 Vandesompele J, De Preter K, Pattyn F, Poppe B, Van Roy N, De Paepe A and Speleman F: Accurate normalization of realtime quantitative RT-PCR data by geometric averaging of multiple internal control genes. Genome Biol 3: RESEARCH0034, 2002.

11 Yang L, Egger M, Plattner R, Klocker H and Eder IE: Lovastatin causes diminished PSA secretion by inhibiting AR expression and function in LNCaP prostate cancer cells. Urology 77: 1508 e1-7, 2011.

12 Mollapour M, Bourboulia D, Beebe K, Woodford MR, Polier S, Hoang A, Chelluri R, Li Y, Guo A, Lee MJ, Fotooh-Abadi E, Khan S, Prince T, Miyajima N, Yoshida S, Tsutsumi S, Xu W, Panaretou B, Stetler-Stevenson WG, Bratslavsky G, Trepel JB, Prodromou $\mathrm{C}$ and Neckers L: Asymmetric Hsp90 N domain SUMOylation recruits Aha1 and ATP-competitive inhibitors. Molecular Cell 53: 317-329, 2014.

13 Iacopino F, Urbano R, Graziani G, Muzi A, Navarra P and Sica G: Valproic acid activity in androgen-sensitive and -insensitive human prostate cancer cells. Int J Oncol 32: 1293-1303, 2008.

14 Lawler PR and Lawler J: Molecular basis for the regulation of angiogenesis by thrombospondin-1 and -2. Cold Spring Harbor perspectives in medicine 2: 1-13, 2012.

15 Roberts DD, Isenberg JS, Ridnour LA and Wink DA: Nitric oxide and its gatekeeper thrombospondin-1 in tumor angiogenesis. Clin Cancer Res 13: 795-798, 2007.

16 Vallbo C, Wang W and Damber JE: The expression of thrombospondin-1 in benign prostatic hyperplasia and prostatic intraepithelial neoplasia is decreased in prostate cancer. BJU Int 93: 1339-1343, 2004.

17 Shiojima I and Walsh K: Role of Akt signaling in vascular homeostasis and angiogenesis. Circulation Res 90: 1243-1250, 2002.

18. Pulukuri SM, Paitbandla S, Patel J, Estes $\mathrm{N}$ and Rao JS: Epigenetic inactivation of the tissue inhibitor of metalloproteinase-2 (TIMP-2) gene in human prostate tumors. Oncogene 26: 5229-5237, 2007.

19 Kojima S, Inahara M, Suzuki H, Ichikawa T and Furuya Y: Implications of insulin-like growth factor-I for prostate cancer therapies. Int J Urol 16: 161-167, 2009. 
20 Mantzoros CS, Tzonou A, Signorello LB, Stampfer M, Trichopoulos D and Adami HO: Insulin-like growth factor 1 in relation to prostate cancer and benign prostatic hyperplasia. $\mathrm{Br}$ J Cancer 76: 1115-1118, 1997.

21 Bello-DeOcampo D and Tindall DJ: TGF-beta/Smad signaling in prostate cancer. Curr Drug Targets 4: 197-207, 2003.

22 Li Z, Wang C, Jiao X, Lu Y, Fu M, Quong AA, Dye C, Yang J, Dai M, Ju X, Zhang X, Li A, Burbelo P, Stanley ER and Pestell RG: Cyclin D1 regulates cellular migration through the inhibition of thrombospondin 1 and ROCK signaling. Mol Cell Biol 26: 4240-4256, 2006.

23 Witt D, Burfeind P, von Hardenberg S, Opitz L, Salinas-Riester G, Bremmer F, Schweyer S, Thelen P, Neesen J and Kaulfuss S: Valproic acid inhibits the proliferation of cancer cells by reexpressing cyclin D2. Carcinogenesis 34: 1115-1124, 2013.

24 Shabbeer S, Kortenhorst MS, Kachhap S, Galloway N, Rodriguez R and Carducci MA: Multiple Molecular pathways explain the anti-proliferative effect of valproic acid on prostate cancer cells in vitro and in vivo. Prostate 67: 1099-1110, 2007.

25 Sidana A, Wang M, Shabbeer S, Chowdhury WH, Netto G, Lupold SE, Carducci M and Rodriguez R: Mechanism of growth inhibition of prostate cancer xenografts by valproic acid. J Biomed Biotechnol: Article ID: 180363, 2012.

26 Sidana A, Wang M, Chowdhury WH, Toubaji A, Shabbeer S, Netto G, Carducci M, Lupold SE and Rodriguez R: Does valproic acid induce neuroendocrine differentiation in prostate cancer? J Biomed Biotechnol: Article ID 607480, 2011.
27 Michaelis M, Michaelis UR, Fleming I, Suhan T, Cinatl J, Blaheta RA, Hoffmann K, Kotchetkov R, Busse R, Nau H and Cinatl J Jr.: Valproic acid inhibits angiogenesis in vitro and in vivo. Mol Pharmacol 65: 520-527, 2004.

28 Stettner M, Kramer G, Strauss A, Kvitkina T, Ohle S, Kieseier $\mathrm{BC}$ and Thelen P: Long-term antiepileptic treatment with histone deacetylase inhibitors may reduce the risk of prostate cancer. Eur J Cancer Prevention 21: 55-64, 2012.

29 Kang H, Gillespie TW, Goodman M, Brodie SA, Brandes M, Ribeiro M, Ramalingam SS, Shin DM, Khuri FR and Brandes JC: Long-term use of valproic acid in US veterans is associated with a reduced risk of smoking-related cases of head and neck cancer. Cancer 120: 1394-1400, 2014.

30. Sharma S, Symanowski J, Wong B, Dino P, Manno P and Vogelzang N: A Phase II clinical trial of oral valproic acid in patients with castration-resistant prostate cancers using an intensive biomarker sampling strategy. Transl Oncol 1: 141-147, 2008 .
Received August 3, 2016

Revised August 25, 2016

Accepted August 26, 2016 